\title{
Some thoughts on dietary requirements of macro-elements for ruminants
}

\author{
By A. C. FIELD, Moredun Research Institute, 408 Gilmerton Road, Edinburgh \\ $E H \perp 77 \mathfrak{F H}$
}

There is no consensus on the needs of ruminants for macro-elements; up to twofold differences in comparable recommendations between authorities can exist (Field, 198I). The major sources of uncertainty lie in the estimates of maintenance requirements and the values ascribed to the efficiency of absorption of macroelements from the diet. Although the extreme example of the former is phosphorus and of the latter calcium, the accuracy of the adopted values for the rest, despite general agreement, is open to doubt. There has been a tendency in the past to consider maintenance requirements and efficiency of absorption as independent entities, but as the former consist essentially of the endogenous secretion which escapes absorption any variation in the latter could alter maintenance requirements.

This paper represents an attempt, much of it speculative, to integrate the processes of absorption and secretion within the digestive tract, to express the processes in simple mathematical terms, to consider the nutritional significance and state of knowledge of the terms and to suggest ways of improving our knowledge.

\section{Absorption of macro-elements in the diet}

The factors controlling absorption (A) of new material into the body proper varies with the element: for $\mathrm{Ca}, \mathrm{A}$ is equal to net requirement, provided the absorption capacity of the gut for $\mathrm{Ca}$ is greater than requirements; for $\mathrm{P}$ and magnesium, $A$ is largely a function of that part of the intake of mineral which is solubilized in the digestive tract prior to the site of absorption and for sodium and potassium, $A$ is approximately equal to the intake of soluble mineral. This assumes complete absorption of soluble $\mathrm{Na}$ and $\mathrm{K}$ (ARC, 1980).

$A$ can be measured directly with radioisotopes, but because such experiments are very expensive and require special facilities, it would be advantageous if $A$ could be predicted from simple non-radioactive measurements. $A$ is dependent upon two processes; the release and absorption of dietary macro-elements in the digestive tract, i.e. $A=\alpha I=\gamma M_{S} I$, where $\alpha$ is the fractional absorption of dietary intake (I) and $\gamma$ the fractional absorption of mineral solubilized in the stomach region $\left(M_{S} I\right)$.

\section{Solubilization of dietary minerals}

The extent and release of macro-elements in the digestive tract is a neglected subject; the obvious site is the rumen where most of the organic matter is digested with a possible additional release of $\mathrm{Ca}$ in the acid conditions of the abomasum (Garton, 195I). There appears to be only one quantitative study; Playne et al. 
(r978) studied the release of minerals from four tropical hays during their digestion in nylon bags in the rumen of cattle and showed that the release occurred in two stages, a major fraction was released within $12 \mathrm{~h}$ and a minor one released at the same slow rate as the digestion of the cell walls. A feature of the results was the large variation in $\mathrm{M}_{\mathrm{S}}$ between hays for certain minerals $(\mathrm{Ca} 0.3$ to $0.6, \mathrm{P} 0.3$ to 0.8 and $\mathrm{Na} 0.4$ to 0.8 ) which, if confirmed for other foodstuffs, would suggest that $\mathrm{M}_{\mathrm{S}}$ is an important determinant of $\mathrm{A}$ for these elements. A surprising result was the incomplete release of $\mathrm{Na}$, as most workers have assumed complete release of dietary $\mathrm{Na}$ during digestion. (ARC, 1980).

\section{Fractional absorption of soluble mineral}

It will be difficult to measure $\gamma$ directly, but it can be calculated from concurrent measurements of $\alpha$ and $M_{S}$ i.e. $\gamma=\alpha / M_{S}$. Although such measurements do not exist at present some general conclusions can be drawn, however, from our limited knowledge of $\alpha$ and $\mathrm{M}_{\mathrm{S}}$.

For $\mathrm{Ca} \gamma$ is not a constant, but varies directly with net $\mathrm{Ca}$ requirements and inversely with $M_{S} I$. To convert net to dietary requirements the factor is $I / \alpha_{\max }$ or $\mathrm{I} / \gamma_{\max } \mathrm{M}_{\mathrm{S}}$. The measurement of $\gamma_{\max }$ requires studies in which the experimental animal has a high $\mathrm{Ca}$ requirement relative to its $\mathrm{Ca}$ intake. Lactating cows and pregnant ewes utilize the $\mathrm{Ca}$ in low $\mathrm{Ca}$ diets with high efficiency $\left(0.84^{-1} \cdot 0\right)$ (Leeuwen \& Visser, 1967; Sykes \& Field, 1972), suggesting that $M_{S}$ may approximate to the conversion factor for net to dietary requirements. Since dietary $\mathrm{Ca}$ is released in the abomasum and absorbed in the small intestine, $\mathrm{M}_{\mathrm{S}}$ must be measured in vivo at the duodenum near to the pylorus or in vitro by subjecting feed residues after rumen digestion to simulated abomasal conditions.

Evidence suggests that $\alpha$ and $M_{S}$ are also of similar order for P; ARC (rg80) has summarized existing information on $\alpha$ for cattle and sheep and found $\alpha$ fell typically in the range 0.4 to 0.8 , a similar range to that found for $M_{S}$ for tropical hays by Playne et al. (1978). For $\alpha$ and $\mathrm{M}_{\mathrm{S}}$ to be positively correlated, $\gamma$ must be high. Field, Dingwall \& Munro (unpublished results) have measured the fractional absorption $(\beta)$ of endogenous $P$ and found it varied between 0.75 and 0.95 . As soluble dietary and salivary $P$ enter the same rumen $P$ pool, $\beta$ and $\gamma$ should be similar, unless a large fraction of soluble dietary $P$ is in a form that cannot be absorbed. This situation is thought unlikely; a large fraction of dietary $\mathrm{P}\left(\mathrm{P}_{\mathrm{T}}\right)$ is in the form of inorganic orthophosphate $\left(P_{i}\right)\left(P_{i} / P_{T} 0.51-0.93\right.$; Playne, 1976) and $P_{i}$ will comprise an even higher fraction of soluble $\mathrm{P}$. Furthermore, the residual soluble $\mathrm{P}$, mainly esters and phosphatides, could be hydrolysed like phytates in the rumen. Thus $\gamma$ could be high and $\alpha$ and $\mathrm{M}_{\mathrm{S}}$ correlated within foodstuffs. This tentative conclusion could be an over simplification as recent studies (see later) have shown that $\beta$ can vary directly with $\alpha$ in sheep consuming the same diet.

In contrast dietary $\mathrm{K}$ and $\mathrm{Mg}$ appear to be always highly soluble in the rumen; Playne et al. (1978) found that 0.8 to 0.9 of $\mathrm{K}$ and $\mathrm{Mg}$ in hay was solubilized in the rumen with little variation between the hays tested. This suggests that $\gamma$ must be similar but a little higher than $a$ and little benefit would be gained by measuring 
$\mathrm{M}_{\mathrm{S}}$ for different foodstuffs. According to this postulate, the large animal variations seen in $\alpha_{\mathrm{Mg}}$ (e.g. $0.05-0.35$, Kemp et al. 196I) should reflect changes in $\gamma_{\mathrm{Mg}}$ However, when inorganic $\mathrm{Mg}$ salts were infused into the rumen (Field \& Munro, 1978; Field et al. 1981) animal variation in absorption was small.

\section{Absorption and mineral intake}

The absorption of many elements is mediated wholly or in part through active transport mechanisms. Such mechanisms become progressively saturated when absorption, either in response to increased animal needs $(\mathrm{Ca})$ or intake ( $\mathrm{Mg}$ or $\mathrm{P})$, is increased. Saturation has been described for $\mathrm{Ca}$ (Duncan, 1958) and $\mathrm{Mg}$ (Field \& Munro, 1978) and more recently for P. Field, Dingwall \& Munro (unpublished results) found that $\alpha_{p}$ fell $(P<0.001)$ by $0.0963 \pm 0.136$ (SE of difference within sheep) when the $P$ intake of sheep on a hay diet was increased from 1.5 to $5.0 \mathrm{~g}$ $\mathrm{P} / \mathrm{d}$ with $\mathrm{P}$ salts (Table $\mathrm{I}$ ). It is, therefore, necessary to define the response surfaces between $\alpha$ and dietary intake for the various macro-elements. For $P$ the surfaces will vary with $P$ requirements, since for a given $P$ intake salivary $P$ can vary inversely with $P$ requirements and reabsorption of salivary $P$ forms the main part of absorption in the gut.

\section{Faecal endogenous loss}

Faecal endogenous loss $(\mathrm{E})$ represents unabsorbed digestive secretions (i.e. $\mathrm{E}=$ $S(I-\beta)$, where $S$ represents digestive secretions) and accounts for $90 \%$ or more of maintenance requirements. To investigate the factors affecting $E$ requires knowledge of either $S$ or $\beta$. Most workers have assumed $\beta$ and $\alpha$ to be the same, despite much evidence to the contrary (Bronner, 1964; Young et al. I966). In a series of studies Braithwaite and his group (see ARC, 1980) have shown that E for $\mathrm{Ca}$ remains constant when $a$ varies from 0.1 to 0.4 . A calculated value for $\mathrm{S}$ (Storry, I96I) and for E (ARC, I980) are similar $(0.5-0.6 \mathrm{~g} \mathrm{Ca} / \mathrm{d})$ suggesting that

Table 1 . Urinary excretion $(U ; g P / d)$, endogenous faecal excretion $(E, g P / d)$, fractional absorption of secreted $(\beta)$ and dietary phosphorus $(\alpha)$ of individual sheep on hay $(\mathrm{I} \cdot 5 \mathrm{~g} P / d)$ and hay plus $P$ salts* $(5 \circ g \mathrm{P} / \mathrm{d})$

(Field, Dingwall \& Munro, unpublished results)

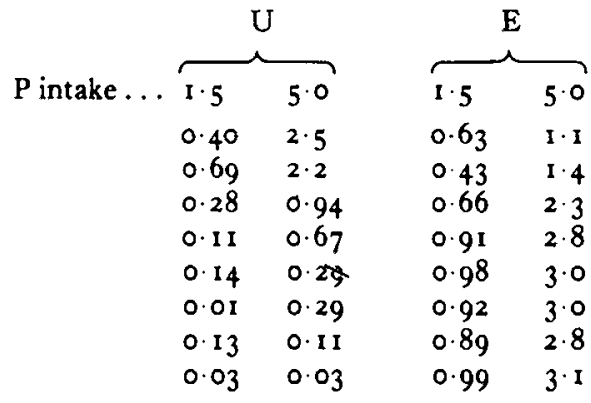

\begin{tabular}{ll}
\multicolumn{2}{c}{$\beta$} \\
\hline .5 & 5.0 \\
0.90 & 0.88 \\
0.92 & 0.87 \\
0.89 & 0.74 \\
0.92 & 0.79 \\
0.84 & 0.69 \\
0.82 & 0.72 \\
0.83 & 0.73 \\
- & 0.77
\end{tabular}

\begin{tabular}{ll}
\multicolumn{2}{c}{$a$} \\
$\overbrace{\mathrm{I} \cdot 5}$ & 5.0 \\
0.82 & 0.79 \\
0.80 & 0.71 \\
0.76 & 0.63 \\
0.63 & 0.58 \\
0.70 & 0.59 \\
0.78 & 0.64 \\
0.71 & 0.61 \\
0.73 & 0.61
\end{tabular}

- $\mathrm{P}$ divided equally between $\mathrm{KH}_{2} \mathrm{PO}_{4}$ and $\mathrm{K}_{2} \mathrm{HPO}_{4}$. 
little or none of $\mathrm{S}$ is absorbed, a surprising result since some $70 \%$ of $\mathrm{S}$ is thought to be secreted proximal to the site of Ca absorption (Storry, 1961). A similar picture is seen for $\mathrm{Mg}$, where $\mathrm{E}$ remains constant despite variation in $\alpha$. A comparison of a calculated value for $\mathrm{S}(0.2 \mathrm{~g} \mathrm{Mg} / \mathrm{d}$, Storry, I961) and $\mathrm{E}(0.12 \mathrm{~g}$ $\mathrm{Mg} / \mathrm{d}, \mathrm{ARC}, \mathrm{1} 980$ ) for a $40 \mathrm{~kg}$ sheep suggests that $\mathrm{S}$ is reabsorbed with a constant $\beta$. Field (196I) has presented radioisotope evidence that $S_{M g}$ is preferentially absorbed in the intestines.

For $\mathrm{P}, \mathrm{S}$ can be taken as the flow of endogenous $\mathrm{P}$ at the duodenum, provided that relatively little $\mathrm{P}$ is secreted distal to the duodenum (Annenkov et al. 1970; Clark et al. 1973) and no $\mathrm{P}$ is absorbed from the stomach region. Field, Dingwall \& Munro (unpublished results) have found that the rate of flow of dietary $P$ at the duodenum was equal to the rate of dietary input. For sheep given hay or a complete pelleted diet, $\beta$ averaged $0.81 \pm 0.0145(n 30)$ with a range from 0.67 to 0.92 . $\beta$ was always higher than but highly correlated $(r 0.7, P<0.001)$ with the corresponding value for $\alpha$. The differences between $\beta$ and $\alpha$ were not constant but decreased as $\alpha$ increased; $\beta-\alpha=0.566-0.606 \alpha(r 0.87, \mathrm{df} 27, P<0.001)$.

\section{Phosphorus homoeostasis}

Animals vary in the way they achieve $P$ homoeostasis; some excrete the $P$ absorbed in excess of requirements in faeces, whereas others use both urine and faeces as routes of excretion (Table I). Animal variation in $\alpha$ and $\beta$ can be used to explain these individual differences which could have a bearing on endogenous faecal excretion and hence maintenance requirements. For a given intake of $P, \alpha$ determines the quantity of $P$ absorbed, $\beta$ the extent of recycling of $S$ i.e. for a mature sheep in zero balance and excreting little $P$ in its urine $S=I / 1-\beta$. At high values of $\alpha$ and particularly $\beta$ the quantities of salivary $P$ needed to excrete all surplus $P$ by the faecal route will exceed the salivary glands' capacity to secrete $P$ and the urinary route must be used to maintain homoeostasis. This is clearly illustrated in Table 2 where the sheep with high values of $\alpha$ and $\beta$ excreted $P$ by the urinary route (Field, Dingwall \& Munro, unpublished results). Furthermore, when $P$ intake of sheep on a hay diet was increased by a ruminal infusion of $P$ salts, the two animals with high $\alpha$ and $\beta$ excreted most of the additional absorbed $P$ by the urinary route (Table $I$ ). The small increase in $E$ in these animals probably reflects the changes in $\beta$ due to saturation of the absorption mechanism. The volume of saliva produced by sheep on a particular diet may play a part in determining the partition of surplus $P$ between the two routes of excretion by influencing the capacity of the salivary gland to secrete $P$.

\section{Individual differences in $P$ absorption}

The studies of Field, Dingwall \& Munro (Tables I and 2) suggest that sheep can be classified loosely according to the efficiency with which they absorb P; a sheep with a high efficiency will have lower maintenance and dietary requirements and a high recycling rate at low $P$ intakes which will meet better the high requirements for $P$ of the microbes in the rumen. Table 3 illustrates the large effect of this 
Table 2. Plasma concentration $(P, m g P / l)$, urinary excretion $(U, g P / d)$, endogenous faecal excretion $(E, g P / d)$, fractional absorption of secreted $(\beta)$ and dietary phosphorus $(\alpha)$ of individual sheep on a complete pelleted diet $(4.6 \mathrm{~g} / \mathrm{P} / \mathrm{d})$

(Field, Dingwall \& Munro, unpublished results)

\begin{tabular}{|c|c|c|c|c|c|}
\hline$P$ & $\mathrm{U}$ & $E$ & $\beta$ & $a$ & Theoretical ${ }^{\star} \mathrm{S}$ \\
\hline 87 & $2 \cdot 7$ & 0.42 & 0.92 & 0.86 & 49 \\
\hline 100 & $2 \cdot 7$ & 0.64 & 0.92 & 0.79 & 45 \\
\hline 90 & 1.8 & $1 \cdot 3$ & 0.85 & 0.66 & 20 \\
\hline 64 & 0.03 & $2 \cdot I$ & 0.68 & 0.45 & 6.5 \\
\hline 57 & 0.04 & $2 \cdot 2$ & 0.74 & 0.39 & 6.9 \\
\hline 57 & 0.05 & $2 \cdot 3$ & 0.79 & 0.41 & 9.0 \\
\hline
\end{tabular}

- Salivary $P(S, g / d)$ needed for surplus $P$ to be excreted in faeces.

Table 3. Dietary requirements $(g / d)$ of phosphorus for lactating ewes; high $(H)$, low $(L)$ and average efficiency of absorption $(A R C, 1980)$

Milk yield $(\mathrm{kg} / \mathrm{d})$

\begin{tabular}{|c|c|c|c|c|c|c|c|c|c|}
\hline \multirow{2}{*}{$\begin{array}{c}\text { Live } \\
\text { weight }(\mathrm{kg})\end{array}$} & \multicolumn{3}{|c|}{ I } & \multicolumn{3}{|c|}{2} & \multicolumn{3}{|c|}{3} \\
\hline & ARC & $\mathbf{H}$ & L & ARC & $\mathrm{H}$ & L & ARC & $\mathbf{H}$ & L \\
\hline 40 & 3.1 & 2.0 & 4.7 & $5 \cdot 3$ & $3 \cdot 6$ & 8.0 & $\begin{array}{l}7.4 \\
8.2\end{array}$ & 5.2 & II. 2 \\
\hline 75 & 3.9 & & & & & & & & \\
\hline
\end{tabular}

ARC, $H$ and $L$ taken to have efficiencies of absorption of $0.60,0.80$ and 0.40 and maintenance requirements of $0.012,0.007$ and $0.015 \mathrm{mg} / \mathrm{kg}$ live weight $/ \mathrm{d}$ respectively.

individual variation in the efficiency of absorption on dietary requirements using the lactating ewe as an example and highlights the need to take such variation into account when formulating $P$ requirements. Since sheep with a high efficiency excrete $\mathrm{P}$ in urine, the large variation in urinary $\mathrm{P}$ excretion between pairs of identical twin cows (Field \& Suttle, 1979) suggests that the same phenomenon occurs in cattle and is partly of genetic origin.

\section{Macro-elements and animal performance}

At present all recommended dietary requirements are based on the needs of the body and no consideration has been given to the possibility that the proposed levels do not provide an optimum environment in the rumen for maximal animal performance on a given diet. Durand \& Kawashima (1979) have recently reviewed the microbial requirements for major minerals and have concluded that these would be satisfied by a dietary supply corresponding to most recommendations for the host. However, for efficient rumen performance the $\mathrm{pH}$ should not decline below 6.0 and $\mathrm{pH}$ values below 6.0 are commonly seen with cereal and mixed concentrate roughage diets, even when the intake of macro-elements are at recommended levels. It is thus possible that there is an additional non-specific requirement for macro-elements to act as cationic carriers for buffering anions like 
bicarbonates, carbonates and oxides. Attempts to improve animal performance with such salts, however, have led to conflicting results (see Wheeler, I980). High intakes of macro-elements can increase the dilution rate in the rumen with possible effects on voluntary intake. For instance, increasing the $P$ intake from $I .5 \mathrm{~g} / \mathrm{d}$ on a hay diet to $5 \mathrm{~g} / \mathrm{d}$ by a ruminal infusion of $P$ salts increased the flow of rumen liquor from 5 to $10 \mathrm{l} / \mathrm{d}$ (Field, Dingwall \& Munro, unpublished results).

\section{Conclusions}

The factors controlling dietary requirements of macro-elements are complex and our knowledge of these factors is insufficient to derive accurate estimates of requirements. There is a need for more work on determining the solubility in the stomach region of the macro-elements in the diet. Although it is too early to know what fraction of variance in $\alpha$ can be attributed to variation in $M_{S}$ between foodstuffs, the possibility exists that a knowledge of $\mathrm{M}_{\mathrm{S}}$ could help to predict the absorbancy of $\mathrm{Ca}, \mathrm{P}$ and $\mathrm{Na}$ without recourse to expensive and time consuming radioisotope experiments. Adjustments in requirements of $\mathrm{Mg}$ and $\mathrm{P}$ due to reduction in absorbability at high intakes of the elements could be introduced, as could safety factors for $\mathrm{P}$ in addition to those for $\mathrm{Mg}$, because of the large individual differences in absorbability.

\section{REFERENCES}

Agriculture Research Council (1980). The Nutrient Requirement of Farm Livestock No. 2. Ruminants. London: Commonwealth Agricultural Bureau.

Annenkov, B. N., Madison, V. L. \& Fomiceu, Ju P. (1970). Sel'skohoz. Biol. 5, 405.

Bronner, F. (1964). Mineral Metabolism, Vol. I IA, p. 349. New York and London: Academic Press.

Clark, R. C., Budtz-Olsen, O. E., Cross, R. B., Finnamore, P. \& Bauert, P. A. (I973). Aust. F. Agric. Res. 24, 913 .

Duncan, D. L. (1958). Nutr. Abst. Rev. 28, 695 .

Durand, M. \& Kawashima, R. (1979). In Digestive Physiology and Metabolism in Ruminants [Y. Ruckebusch and P. Thivend, editors]. Lancaster: MTP Press.

Field, A. C. (196r). Br. F. Nutr. 15, 349 .

Field, A. C. (1981). 4th Annual International Minerals Conference, Mundelein, International Minerals and Chemical Corporation p. I.

Field, A. C., Dingwall, R. A. \& Munro, C. S. (1981). Proc. Nutr. Soc. 40, 72 A.

Field, A. C. \& Munro, C. S. (1978). 7. agric. Sci., Camb. 89, 365.

Field, A. C. \& Suttle, N. F. (1979). F. comp. Path. 89, 43 r.

Garton, G. A. (195I). F. exp. Biol. 28, 358.

Kemp, A., Deijs, W. B., Hemkes, O. J. \& Van Es, A. J. H. (196r). f. agric. Sci., Camb. 9, 134. Leeuwen, J. M. van \& Visser, M. de (1967). Tijdsch. Diergeneesk 101, 825.

Playne, M. J. (1976). Rev. Rural Sci. I I 1, P. I55. Armidale: University of New England Press.

Playne, M. J., Echevarria, M. G. \& Megarrity, R. G. (1978). F. Sci. Fd Agric. 29, 520.

Storry, J. E. (1961). Nature, Lond. 190, I 197.

Sykes, A. R. \& Field, A. C. (1972). f. agric. Sci., Camb. 78, 109.

Wheeler, W. E. (1980). 7. anim. Sci. 51, 224.

Young, V. R., Lofgreen, G. P. \& Luick, J. R. (1966). Br. f. Nutr. 20, 795. 